\title{
A Team Teaching in Web Programming Course*
}

\author{
Zhang Jia \\ Hangzhou International Services Engineering College \\ Hangzhou Normal University, HZNU \\ Hangzhou, China \\ zhangjia@hznu.edu.cn
}

\begin{abstract}
With the rise of the Internet, the engineering personnel training needs should be closely combined with social needs. According to the characteristics of the Web programming course based on flipped classroom teaching, the paper proposed the implementation of Team Teaching and gives the teaching implementation plan, which is composed of the teaching content, teaching team, evaluation system and so on. It makes a beneficial exploration to the application of the team teaching in the flipped classroom in the university.
\end{abstract}

Keywords-Team teaching; Web programming course; Flipped classroom; Educational innovation

\section{INTRODUCTION}

Nowadays, Web programming course is one of the important computer science courses, which is set after the programming courses. The course trains students to achieve the comprehensive understanding of the web front-end development, which requires strong practicality and innovation. In the arrangement of the course, the content has been divided into the page structure and layout, the page behavior, the server-side scripting and the project. The four sections include all what are needed in the front-end development; meanwhile the verification exercises and the complex stage exercises are designed. It is hoped that the students' the ability of practicality, innovation and cooperation would be improved after learning and training in the course.

Although it is good to focus on engineering practices in the Web Programming course, it still faces many operative problems. Firstly, the range of the Web development can change from developing the simplest static single page of plain text to the most complex web-based Internet applications, so it has systemic and complete of the key knowledge and operation rules. Secondly, students need not only the knowledge about Software Engineering, Database and Data Structure to develop the complex Web-based Internet applications, but also the integrate ability to use the knowledge of web-programming course synthetically. Finally, students should be instructed properly and evaluated accurately in one stage during developing the last integrated project. Obviously a teacher could not finish all the teaching tasks under the traditional arrangement; moreover it's impossible that all the study tasks have been finished in the classroom because of the limit in class hours.

Today the flipped classroom is more and more popular, and scholars have done more and more researches. The educational mode of flipped classroom absorbs the advantage of MOOCs, moves forward a single step and has become into the blended educational form integrated online open courses with classroom teaching. It integrates the teacher-center learning and the student-center learning, and reverses the traditional educational arrangement. Students take the initiative to acquire knowledge using teacher-student interaction, self-learning based on problems and resources and collaborative inquiry. The integration ensures either the systemic and complete knowledge or students' active and effective learning. It can be seen clearly that the flipped classroom emphasized students' personality and self-control. Students can distribute their time on learning by themselves outside classroom according to their own learning pace, discuss with their classmates and teacher and finish the exercises and labs in classroom. So students may get a bigger self-control on learning while teachers positioned on "learning with the help and guidance" role in the flipped classroom. It delivers instructional content usually outside of the classroom and allows students to choose the most suitable time or way to acquire new knowledge. The process of knowledge internalization occurs in classroom by way of communicating and discussing among students and teachers. It's in line with the law of human cognition and conducive to human knowledge's tradition and innovation.

In summary, it's impossible to teach all of the Webprogramming course's contents by a single one either learning based on engineering practice or the implement of the flipped classroom. In such circumstance, the team teaching becomes a more suitable and actual educational mode. This paper analyzes the course, the flipped classroom and team teaching's characteristics, and then proposes a team teaching mode to arrange and combine contents among the teachers in a group, to evaluate students' learning and to carry out individualized instruction according to their characteristics so as to reflect the rich humanistic care.

In this paper, Chapter 1 describes the status of Web programming course, the characteristics of the flipped classroom and necessity of the implementation of team teaching in Web-programming; Chapter 2 introduces briefly the background of the flipped classroom and team teaching; Chapter 3 gives a proposal on how to implement team teaching in the Web programming course based on the flipped classroom; and the final chapter is the conclusion.

\section{BACKGROUD}

\section{A. the Team Teaching}

Team teaching is a new educational mode developed from the basic principles on the basis of collaboration. Professor J. 
T. Shaplin in the Washington University gave the definition of team teaching, which is a teaching form carried out by a teaching group including with more than two teachers who arrange the specific contents together and undertake their own teaching contents.

A teaching group is built under the premise the cooperation between the members, the cooperation between the team and environment and the cooperation on educational evaluation. So it can be seen from the implementing process that the implementing conditions of team teaching includes three points Firstly, the strong policy from university leader is assurance of the implementation of team teaching. Secondly, teachers should have enough professional autonomy. Thirdly, a teaching group should be built on cooperation.

In recent years, with the continuous progress in the research and practice of team teaching, the theory is further developed. The scholar considered that teaching system should be thought of an open dynamic system in team teaching mode. The variable factors including teachers, students, the educational objectives and teaching media in the teaching process should have always been kept in a collaborative status. Teachers try their best to eliminate uncoordinated generated dissipation and finally the destination is to achieve the process optimization of the complex teaching system.

\section{B. the Flipped Classroom}

The flipped classroom is a new teaching mode proposed by two senior school chemistry teachers from USA. It solves the student's learning problem having stayed at home for a long time. The beginning form is that the student has watched the teaching videos at home before the class and did the exercises under the guidance of the teacher in the classroom. Later, it was developed into the blended educational form integrated online open courses with classroom teaching after absorbed the advantage of MOOCs.

\section{THE CONSTRUCTION OF TEAM TEACHING}

\section{A. The Teaching Contents of Web Programming Course}

After classifying the Web programming course's knowledge, the contents are divided into four sections: (1) Page structure and layout (16 lessons). Students can design and develop the responsive page using HTML5 and CSS3. (2) Page behaviors (16 lessons). Students can write JavaScript code to change the page's appearance and status, study event-driven mechanism and realize the page elements' dynamic effects using native JavaScript or jQuery. (3) Server-side scripting (16 lessons). Students can understand how to work with HTTP protocol, write server-side scripts to access the MySQL database using PHP and realize the asynchronous refresh in the page using AJAX. (4) Course projects (16 lessons). Teachers give the projects' list to students, introduce every project's industry background briefly and analyze projects' functional requirements and the key parts in the process of project's realization. Students choose one of the projects and realize it. In order to keep pace with industry, technology seminars are arranged in the term. The engineers are invited into the class to introduce the popular technology and practical skills of web programming in industry.

Considering the flipped classroom's features, students have learned new knowledge outside classroom using micro videos, books, reference materials and examples provided by the teachers and discuss with their classmates and teachers. So teachers should record every student's performance in classroom and score it, which can be the questionnaire, the exercises, the stochastic quiz and so on to check students' learning outside classroom.

\section{B. The Formation of a Collaborative Teaching Team}

Team teaching mode requires that the teaching group should be corporate with each other in the process of collaborative teaching. It's a big challenge for the teacher who has been accustomed to work by oneself. The support mode is used in practice what is one of team teaching modes. It requires the group arrange the teaching contents and evaluate students' performance together. Teachers can make the teaching slides, the micro videos and other teaching materials used in class by themselves and play their own role in the teaching process.

Before building a teaching group, teachers should notice the following three points: (1) Cooperation and communication Although teachers are designated different work according their own interest and specialty, they should communicate on the teaching feedback from every period during the teaching process with each other and adopt different collaborative form in different period. (2) Differences and complementarities between members. Leader selects the different specialty and characteristic member based on the principle of voluntary to ensure knowledge structure and teaching style's complementarities. (3) The teaching form's flexible diversity. Team teaching adopts the different combinations with many teaching forms according to teachers' style and students' personality. Therefore, it has big flexible diversity.

\section{C. the Multi-Dimensions Evaluation}

The team teaching can significantly improve the educational quality and efficiency what is applied in Web programming course. But how to evaluate students' learning is considered as one of the problems under the collaborative teaching carried out by several teachers. If teachers give scores according to the results at the end of term, students would not attend to discussion in classroom carefully, and some of them even would be in classroom because of the attendance score. So such result evaluation is not suitable for the flipped classroom.

The single results evaluation form should be transformed into a multi-dimensions evaluation form step by step. Teachers should add the report, the discussion outline, the tracking records and so on in the learning process of the former three sections, so that teachers can inspect student in multi aspects, and then give the score according the student's overall performance. In every learning period, the student's period evaluation includes the self-evaluation, evaluation with each other and the score given by teacher and the final score is the integrated one. Under this evaluation form, teachers can supervise students' learning progress, help some students to 
solve their problems and adjust the learning progress according students' learning status timely. At the same time, students change their attitude on learning more effectively and attend the discussion more actively.

The relative perfect multi-dimensions evaluation based on students' process performance in Web programming course could be supervised and ensure teachers to cooperate seamless, the students' learning progress outside classroom and the smooth discussion in classroom.

\section{CONCLUSION}

The objective of Web programming course is to train programming well, learning quickly, strong sense of innovation and cooperation with each other well for students. However there are many variable factors in the educational process and it is hard to implement in order to achieve the educational objective. Team teaching is a flexible educational method and has been carried out by a teacher group, and the different special skill teacher in this group will teach students in cooperation mode. It's a benefit attempt for implementing the flipped classroom. Now there are few educational practice results in universities in China, and we can do thorough and systemic research in the educational domain.

\section{ACKNOWLEDGMENT}

The work is supported by the Teaching innovation project of Hangzhou Normal University (No. ZX13016002005030)
[1] Danjie Qian, Weiping Zhang. Review of the domestic research on collaborative teaching $[\mathrm{J}]$. Teaching and managemen, 2012.5.

[2] Ning Miao, Xiangyang Mu, Shengli Pei. The content and innovation of information management subject under the background of big data $[\mathrm{J}]$. Journal of Henan radio and TV University, 2014, 27(3):85-86.

[3] Haiyan Liu. The model of interdisciplinary science and education in University of Michigan [J]. High education in China, 2008(17):60-62.

[4] Xiangyang Liu, Jun Cheng. The differences of students' cognitive styles and cooperative teaching [J]. Journal of the Chinese Society of Education, 1994(3):32-33

[5] Shaofei Wang. Collaborative teaching model and strategy [J]. Primary and secondary schooling abroad; 2005(3):33-35.

[6] Jingchuan Li, Yueguo Zhang . "Three Four Five or six " The operation of the flipped classroom [J]. Information technology education in primary and middle schools, 2012(11):82 - 83.

[7] Xiaoliu Zhong, Shuqiang Song, Lizhen Jiao. Instructional Design Research Based on flipped classroom in information environment [J]. Open education research, 2013(1).

[8] Jinlei Zhang, Ying Wang, Baohui Zhang. Research on flipped classroom teaching mode [J]. Journal of Distance Education, 2012(4):46-51.

[9] Hong Wang, Wei Zhao, Li Sun, Hongxia Liu. Design of flipped classroom teaching model $[\mathrm{J}]$. Modern educational technology, 2013(8):5-10

[10] Yueguo Zhang, Yujiang Zhang. Perspective "flipped classroom" [J]. Information technology education in primary and middle schools, 2012(3):8-10.

[11] Tieyan Yin, Yu Peng. Review of flipped classroom research [J]. Contemporary Education Forum, 2015(1):99-101.

[12] Chen Li , Jie Li, Weiquan Liang . Research status of flipped classroom in China -- Based on the content analysis of Periodical Literature[J]. China's modern educational equipment, 2014(15):105-108.

[13] Da Yin . The localization of "flipped classroom" based on the theory of ecosystem [J]. Education and teaching research, 2014(9):16-19.

\section{REFERENCES}

